\title{
Piezoelectricity: a literature review for power generation support
}

\author{
Denis O. Urroz-Montoya1, a , Jeffrey R. Alverto-Suazo1, b, Julio R. García-Cabrera ${ }^{1, \text { c }}$ and Cesar H Ortega-Jiménez ${ }^{1,2,3, d, e, f}$ \\ ${ }^{1}$ Universidad Nacional Autónoma de Honduras (UNAH), Ingeniería Mecánica, Honduras \\ ${ }^{2}$ Universidad de Sevilla, Doctorado GENI, Sevilla, Spain \\ ${ }^{3}$ Universidad Tecnológica Centroamericana (UNITEC), Facultad de Postgrado, Honduras

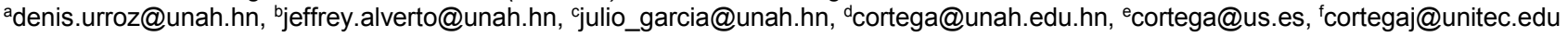

\begin{abstract}
It is undeniable the potential of piezoelectric materials as an energy source. However, do current methods have the potential to be applied widely. To answer this, we require to know their current value according to socio-urban and environmental conditions. This paper presents the first literature review to study the ways of most successful piezoelectric forms of generation, implemented today, and a comparison between them according to their energy potential, as well as the socioeconomic implications presented. Results give a clearer picture of the challenges and advantages of piezoelectric materials as a means of power generation support, showing the positive practical implications of the implementation of piezo systems.
\end{abstract}

\section{Introduction}

The lack of urban physical space and steady growth of the energy matrix, allow us to envision a future where the constant improvement of the existing matrix, becomes an essential practice towards more intelligent and self-sustainable cities [1]. Thus, following Priya and Inman's solution, we go along their piezoelectric solution by their quote in p.14 [2]: "One of the possible solutions to this problem are called energy harvesting techniques, these allow collection of residual energy from environmental sources, clean and free."

However, this is a challenge, since creating new options to satisfy the growing energy needs, leads to an essential increase in $R \& D$ of such power generation support. On the subject, do we imagine power generation being supported just by traveling on public roads, and/or visiting the park and/or, while commuting to work, and/or exploit the waves swing of the seas? Since 1880, this is possible thanks to the phenomenon of piezoelectricity, discovered by the Curie brothers [3]. The concept and breadth of applications of piezoelectric materials have evolved over time. Thus, considering one of the most recent definitions of such phenomenon, we quote, Ali B. and A. Mashaleh in p.2 [4]: "Piezoelectricity is a property for some materials which lies in generating electrical voltage when mechanical force is subjected into it and vice versa". Currently, there are various studies for the use of this phenomenon, ranging from special bricks on the sidewalk for pedestrians, pressure points in roadways and railroads [5], up to specialized breakwaters for coastal zones $[5,6]$. Hence, the literature in this regard seems to show some glimpse of the use of piezoelectric materials, indicating that they could have an interesting future for supporting power generation
$[7,8]$.

Considering the above, the purpose of this paper is to summarize methods of energy harvesting and their socio-economic implications, of applying such methods of power generation, which does not completely alter urban spaces. By this, piezo electrical solutions to the steady growth of the energy matrix, and a comparison of energy production between the methods, as well as a comparison with other energy parameters to measure its applicability are sought [9].

The structure of this article continues with the reference framework based on methods of collecting energy through piezoelectric materials and the resulting propositions. Then, in Section 4 the results of the literature review are presented. In the last section, we present a brief discussion of our findings and implications of this technology so that it can encourage the various players in the productive sector to bet by emerging technologies that can integrate the development of cities and their inhabitants.

\section{Framework and proposals for piezoelectricity}

The key methods of piezoelectric materials for power generation support, their advantages and disadvantages, as well as special cases of applications and propositions are next presented. They are followed by a study on the environmental impact and economic aspects of piezoelectricity of power generation and a corresponding proposition.

Corresponding author: ${ }^{\mathrm{d}}$ cortega@unah.edu.hn 


\subsection{Piezoelectric tiles}

If considering that a tile is a brick floor, whereby passing pedestrians, electricity is obtained when people walk through tile implementing the principles of piezo generation materials, which may be considered micro power generation for auxiliary power [10]. On this line, S. Joo et al, proposes the following classification in p.1: "Two ways of generating power from piezoelectric modules are available: hitting and vibrating." By hitting, they argue that such material will undergo a load directly on piezoelectric modules. On the other hand, in the vibration method, where loads are merely superficial, the latter has a wider application because of its increased durability. However, due to the amplitude of the surfaces, it can be installed in wider areas, making it a source of macro power [11].

Since people must mobilize, walking almost anywhere, what better than to choose crosswalks, office buildings, shopping malls or even discotheques to take advantage of that energy and create electricity. This means an innovative way to generate clean energy, and its success is guaranteed because mankind will not fail to move from one place to another by walking as the raw material. Thus, we have Proposition 1: There is useful generation by energy harvesting through piezoelectric tiles.

\subsection{Piezoelectric pavement as energy collector by traffic}

Piezoelectric pathway involves placing devices on asphalt, able to transform the pressure and vibration exerted by the vehicles into electric power. On the one hand, this sort of energy as electrical pulses must be rectified and transformed to obtain a storable and usable energy. On the other hand, in recent decades it has become a priority to build new roads by the significant increase in the vehicle fleet [12]. Thus, as Mike Gatto says [13]: "A major source of renewable energy is right beneath our feet -- or, more accurately, our tires. California is the car capitol of the world. It only makes sense to convert to electricity the energy lost as cars travel over our roads.", specialized sections of roads have been designed to convert vibrations caused by cars into energy in places such as Israel, Japan, the United States and Colombia, just to name a few countries [10]. This application is somewhat new and interesting because a truck, for instance, can generate a large amount of potential, once it travels on the road that has the piezoelectric material layer under the asphalt. This layer also serves to obtain data such as speed, weight and frequency of passing vehicles. Further, there is literature of high generation capacity with as short as one-kilometer road stretches, using piezoelectric technology [14]. Given such prototype tests of energy harvesting techniques, with real practical grounded applications [15], it is a great potential which may be used by the transit of vehicles on these devices. Besides, when talking about roads where heavy vehicles cross by, the potential is greater, even to the point of achieving independence from the network and indirectly recovering the investment from these piezoelectric devices. We then present Proposition 2: Designing new roads where heavy traffic is expected, by implementing piezoelectric pavement might help for power generation support

\subsection{Railways adapted with piezoelectric devices}

The generation of electricity through the train tracks are an adaptation of the application for power generation from roads by means of pavements with piezoelectric elements [16]. The advantage with the application in the railways is that it is guaranteed that pressure will be exerted at the same point repeatedly [14]. This is because the deformable piezoelectric devices are in the joints that make up the support of the rails, which are connected to the rest of the equipment so that the energy collected can be used $[4,9]$. Whether for power supply of trains, for signals of the road or even for supply toward the general power grid, each one may be possible because with the passage of the trains it is estimated that it could generate at least some $120 \mathrm{kWh}$ of clean energy and at the same time provide information such as speed, weight and number of wheels [17]. Finally, this type of transport emits inevitably vibration and pressure to specific points of the rails, thus reaching self-sustaining signaling pathway, or even better yet, if they are electric trains, it may reduce the requirements for the electricity network and in such case provide power to the grid [14]. Considering this, we have Proposition 3: Adapting piezoelectric devices to railways as energy harvesters might help for power generation support.

\subsection{Piezoelectric breakwater}

The wave energy is a huge source of potential energy, clean, which can be exploited by piezoelectric devices. In addition, given the large number of coastal areas, since $70 \%$ of our planet is made of oceans, it is a great amount of electricity which is calculated could be obtained through the waves, you can even install devices on buoys or floats offshore, but to be profitable these devices must be large $[5,6]$, this system would have a minimal impact on the marine environment as it could be used to have useful sensors for navigation [17]. Due to the size of this resource, savings will be provided in the installation of lines for coastal areas that do not have electrification, along with the benefit that it is a clean and renewable energy, which is being harvested in this way. We then preset Proposition 4: Harnessing the natural potential of the seas and oceans energy through piezoelectric breakwater might help for power generation support.

\subsection{Environmental impacts and piezoelectricity}

If there is something common to all methods of implementation of piezoelectric materials as a means of generating energy, it is that they obtain electricity from structures or activities forming part of the current routines of human beings. Such materials have come a long way, and recently, they had a huge impact on the scientific community, considering that the first paper in which the term "nano piezoelectric generator" was used is of ZL Wang, who is the father of this concept [18]. Based on the Web of Science database, this paper has been cited more than 3500 times in a decade (2006-2016) [19]. In other 
words, there is research for alternatives to mitigate the environmental impact as a priority. You just need to look at the different weather events that challenge us to imagine relational cities, where all members of society and productive sectors, seek to address climate change [20]. In addition, there is the importance of supplying energy demand, lack of physical space available in fully urbanized areas. In the context of a complex global energy situation, environmental pollution and climate change, will require eco-friendly technology applications. On this matter, the impact caused to the environment by the piezoelectric materials is minimal, as they adapt to existing structures without collateral damage [21]. When analyzing the energy matrix of developed countries, we can see a clear trend to transform what we know as methods of conventional generation (fossil, nuclear, thermal, etc.), in practices that respect the urban space and biodiversity, coupled with the relentless pursuit of the integration of the individual as the protagonist of this transformation [22]. Furthermore, the climate change and the way we are forced to seek solutions for power generation in the friendliest way for the environment, methods of harvesting energy through piezoelectric materials are positioned as an alternative for the future, allowing us to have Proposition 5: Piezoelectricity can generate energy without affecting the environment, which is harvested and adapted with existing urban spaces as power generation support for the electrical grid.

\subsection{Economic implications of energy harvesting methods from piezoelectricity}

The multidimensional relationship of renewable energy projects, no matter what kind they are, must also consider the issues from a one-dimensional perspective, such as society and the energy market [23]. Private enterprise and even the political framework of government are apparently involved for the relevant care of environment, which is extremely necessary to create an atmosphere of competitiveness against traditional forms of generation, to which countries had to stick, partially for the lack of private investment on alternative methods of harvesting energy [24]. Hence, one of the biggest challenges are the costs that have the storage from piezoelectric materials, so as to encourage both innovation and public-private support [25]. Consequently, socioeconomic analysis should be conducted, and it is appropriate, especially in private investment projects in which profitability plays an important factor. Given this, it is essential to choose investment projects that are well adapted to the frames that investment offers. Public policies that encourage investment are essential for the growth of countries, especially when it comes to the transparency of implementation processes, as well as from the support of banking institutions through financing projects with long-term return. Therefore, we present Proposition 6: Developing and clarifying public policy play a decisive role for the methods of harvesting energy not only for being innovative but friendly to all parts involved, in order to be positioned successfully

\section{Research methodology}

To achieve the desired objective of this paper, a detailed review of the literature is required, following the methodology proposed by [26]. Thus, this part seeks to analyze the literature in the area of piezoelectricity as a power generation support, by placing within the global context.

As far as data source, the collection of information was carried out from various websites, such as Science Direct, JSTOR and EBSCO. Complementarily, we also consulted secondary sources such as Google Scholar, Research Gate and Academia, where we sometimes requested directly to the author. We found papers from 1994 to 2019, by choosing those whose content have information on methods of generation and energy harvesting by means of piezoelectric devices.

As far as study selection, it was done in two stages. Initially, a general search was conducted to probe the recurring parameters in the search, years and languages considered as primary written in English and Spanish, thus collecting a total of 51 documents including papers, theses and books. The document selection criteria were based on the leading authors in the field, as they are the ones who were preferred for decision criteria and citation in our paper. At this first stage of review 14 documents were ruled out. On the second stage, 7 were discarded by means of reading their abstracts, thus proving useful 34 for the literature review. The search strategy was to use keywords such as piezoelectricity, power generation, energy harvesting. We also verified documents by date, where those with a range within at least 5 years old are the most relevant to our study.

\section{Results}

As said before, 51 documents were initially collected. By stage two, there were 34 documents left for review. Useful documents in first stage: Piezoelectricity in general: 7, piezoelectric tile: 5 , piezoelectric devices pavements: 10 , piezoelectricity wave: 5, environmental issues: 3, economic issues: 5 , generating solar support: 2. Discarded documents in first stage: Types of piezoelectric materials: 5, operating frequencies of piezoelectric materials: 3, piezoelectric microcircuits: 1, piezoelectric crystal structures of materials: 2, wind generation: 1, micro generation: 2. From such literature, we found that the search for energy harvesting methods has grown exponentially in recent years. According to the forecast of piezoelectric energy use from IDTechEx, the development of such industry was calculated from \$ 145 million in 2018 to $\$ 667$ million by 2022 [27]. Further, the interest in finding methods that respond to the growing energy needs inspire researchers to explore the potential of piezoelectric materials converting mechanical energy into electricity. From such piezoelectric materials, we explored in this review the ones that are the most researched and implemented around the world, to establish a comparative thereof. Hence, after reading the contents of the 30 documents from stage two, we were left with four papers in Table 1. The table is constructed with data from studies that 
have been carried out in different parts of the world and give us some key values extracted from documents in which the authors provide data from places where they have developed prototypes of application of such technology, while omitting the theoretical data presented and focusing on practical data, collected from various authors, which with future research and improvements on the piezoelectric technology, could have a greater energy production. Furthermore, as seen in Table 1, it is in the rails, where there is more potential power generation, exceeding by $343 \%$ to the second one, piezoelectric pavement. The piezoelectric railway could keep lighted 2400 sodium lamps 12 hours a day for 30 days. This shows that the potential of piezoelectricity as a means of power generation support in places where one of its generation methods is usable. Each method described here has potential for generation, according to their field and area of application. For instance, when comparing with the power consumption of street lighting, piezoelectric pavement provides $125 \%$ of the energy required in the case of sodium lamps and $287 \%$ in the case of led lamps [31]. This show a range of applicability of piezoelectric materials as a means of harvesting energy. Piezoelectric energy production may probably not yet be enough for the application site to really become independent of the power grid, but it may return self-sufficient networks, while generating clean energy.

Table 1. Comparative generation capacity.

\begin{tabular}{|c|l|l|c|}
\hline $\begin{array}{c}\text { Generat } \\
\text { ion } \\
\text { method }\end{array}$ & \multicolumn{1}{|c|}{$\begin{array}{c}\text { Energy } \\
\text { production }\end{array}$} & Place of harvest & $\begin{array}{c}\text { Sourc } \\
\text { e }\end{array}$ \\
\hline $\begin{array}{c}\text { piezoele } \\
\text { ctric } \\
\text { tiles }\end{array}$ & $27[\mathrm{kWh} /$ day $]$ & $\begin{array}{l}\text { Macquarie } \\
\text { University in } \\
\text { Sydney, Australia }\end{array}$ & {$[28]$} \\
\hline $\begin{array}{c}\text { piezoele } \\
\text { ctric } \\
\text { paveme } \\
\text { nt }\end{array}$ & $840[\mathrm{kWh} /$ day $]$ & $\begin{array}{l}\text { Avenida Boyaca } \\
\text { Avenue and Calle } \\
17, \text { Bogota, } \\
\text { Colombia }\end{array}$ & {$[29]$} \\
\hline $\begin{array}{c}\text { Piezoele } \\
\text { ctric } \\
\text { railway } \\
\text { s }\end{array}$ & $2880[\mathrm{kWh} /$ day $]$ & Israel & {$[7]$} \\
\hline $\begin{array}{c}\text { piezoele } \\
\text { ctric } \\
\text { breakw } \\
\text { aters }\end{array}$ & $4[\mathrm{kWh} /$ day $]$ & $\begin{array}{l}\text { Cantabria, } \\
\text { Santander, Spain }\end{array}$ & {$[17]$} \\
\hline
\end{tabular}

In relation to similar applications, a tile solar generation of support in the bike path made in Tourouvre-au-Perche, in France produces $409 \mathrm{kWh} /$ day [30] A similar project was also installed in -Krommenie and Wormerveer, Amsterdam [31]. With such literature comparison, it is demonstrated that power generation in pavement, from piezoelectric materials are superior to solar pavement.

\section{Discussions and conclusions}

A summary of answers to the six propositions from Section 2 , by an analysis of the compliance of each one. The table below shows total acceptances of propositions 1-3, and 5, as well as partial acceptance to propositions 4 y 6 . We next, go over the six propositions. Proposition 1: The growth of the projects that take piezoelectric tiles as a generation principle is exponential. In Table 1, Comparison of Generation, you can observe some specific performance data that vary according to the area and the technology applied, representing energy that could be perfectly used for lighting either a street or a house. The companies dedicated to the installation of tiles have contracts in the largest corporations in the world, such as Google, Cisco, Siemens, and the case of Pavegen Industries, leaves in evidence the enthusiasm and potential that is identified in this way of harvest of energy. Proposition 2: On the other hand, the possibility of obtaining electric power from unusual sources is a concept that continues to expand. For example, roads that apply piezoelectric materials and generate electricity by the passage of vehicles are a reality and have a great future, according to what HJ Xiang says, who presents an analysis of the energy collection of roads. Currently, although there are several projects around the world, a very particular case is that of the company Innowatech, who under the No. 4 highway in Israel placed piezoelectric generators that were then covered with asphalt, due to the success of the pilot project it is planned to place the generators in more roads of the country's road system [32]. Proposition 3: In addition to the above, the generation capacity in railways is enormous, as shown in Table 1 . We can see that the piezoelectric railways are those with the greatest generation potential. P. Kumar, in his work "Piezo-Smart Roads," states that the advantage offered by the structure and nature of the means of transport is unparalleled to be exploited through piezoelectricity [14]. On the other hand, there are countries with an average of $40,000 \mathrm{~km}$ of rail network in which this application would have enormous success in the future [33]. Proposition 4: Not only can energy be generated on land with pedestrian crossings, streets and roads, there is also a huge challenge in determining ways to take advantage of sea waves to produce energy. There are already projects that take the basic principle of piezoelectric generation and adapt it. Y. Yan, and S. J. Priya, affirm in their work, Piezoelectric Materials for Energy Harvesting, that energy can be generated through the sea and that it is friendly to the environment [5]. The challenge remaining is a large pilot project of these systems to be able to know the real potential of it. However, from Table 1, we can identify early explorations of energy capacity of this method. Proposition 5: On the other hand, there is no doubt, the importance of climate change is growing, Far PR, in his work "Climate change and the relational city", says that if we create a future in which all the parts that make up the productive sector, converge and work together towards the same north [19]. We can then affirm that we have achieved sustainable development. Piezoelectric technology is not exempt from this and seeks the incorporation of forms to generate energy to existing structures, without damaging them, nor generating emissions, due to the nature of its process, which requires mechanical strength, evidenced in the methods of generation described through this review. Proposition 6: One of the main challenges of piezoelectric energy generation methods is to position oneself in the market to 
be able to establish itself in all possible areas of application. For this, the participation of the state apparatus is a facilitator of the process.

It is necessary that innovation be encouraged, and the licensing and financing processes become more transparent. N. Edomah, affirms in his work: Economics of Energy Supply, the complexity of the processes of creation of energy projects in terms of investment and the complexity of the state apparatus [24]. In recent years, renewable energy has increased considerably around the world; specifically, the percentage of energy from renewable sources in the final gross consumption of energy has almost doubled in recent years, in the case of the European Union, they have gone from approximately $8.5 \%$ in 2004 to $17.0 \%$ in 2016 [34]. This positive evolution has contributed to the binding state objectives aimed at increasing the percentage of energy from renewable sources, which were established in European Union agreements. The study presents some limitations as opportunities for future research, in subjects such as the viability and economic profitability of more advanced projects, due to the little diffusion of piezoelectricity in the industry. In addition, as of now there is still very little data available to perform a comparison that determines its competitiveness with traditional methods of energy generation, urging for more empirical and experimental research. Piezoelectric materials, as protagonists of harvesting energy support not only represent a solution to explore, but also an opportunity to encourage innovation, it is a new field of study that deserves to be analyzed. Therefore, our paper has presented a review from many perspectives of the piezoelectric energy and its future, determining its relevance in an increasingly changing world and thirsty for new options, which are viable and whose impact be as small as possible. Finally, this represents a first literature review about piezoelectricity as a support to power generation, showing the practical implications of the implementation of piezoelectric systems.

\section{Acknowledgments}

The authors wish to acknowledge the support of UNAH.

\section{References}

1. L. Mora, M. Deakin, and A. Reid, "Strategic principles for smart city development: A multiple case study analysis of European best practices," Technol. Forecast. Soc. Change, no. July, pp. 0-1, 2018.

2. A. Erturk and D. J. Inman, Piezoelectric energy harvesting. Wiley, 2011.

3. H. Office, K. Park, R. West, P. Wa, P. O. Box, and W. P. Wa, "1 of 6," pp. 1-6, 2008.

4. B. Ali and A. Mashaleh, "Power Generation Using Piezoelectric Materials," no. December, pp. 0-4, 2018.

5. D. Maurya, Y. Yan, and S. J. Priya, "Piezoelectric Materials for Energy Harvesting," no. March 2015.

6. S. B. Kordmahale, J. Do, K. Chang, and J. Kameavoka, "Low Cost and Piezoelectric based Soft Wave Energy Harvester Abstract:” 2018.
7. F. Laumann, M. M. Sørensen, R. F. Jul Lindemann, T. M. Hansen, and T. Tambo, "Energy harvesting through piezoelectricity - Technology foresight," Energy Procedia, vol. 142, pp. 3062-3068, 2017.

8. X. Xiaochen, G. Dongwei, Y. Hailu, and H. Ming, "Application of piezoelectric transducer in energy harvesting in pavement," Int. J. pavement Res. Technol., vol. 11, pp. 389-395, 2018.

9. E. Pineda Perez and S. Velázquez Alfaro, "Design and implementation of a piezoelectric generator tile, to power a low power lighting system," Thesis, Instituto Politécnico Nacional, 2016 (in Spanish).

10. S. Joo et al., "Designing and manufacturing a piezoelectric tile for harvesting energy from footsteps," Curr. Appl. Phys., vol. 15, no. 6, pp. 669-674, 2015.

11. H. J. Xiang, J. J. Wang, Z. F. Shi, and Z. W. Zhang, "Corrigendum: Theoretical analysis of piezoelectric energy harvesting from traffic induced deformation of pavements (2013," vol. 095024.

12. M. Gatto, "Piezoelectric roads for California | Off Grid Energy Independence."

13. "Piezoelectric Energy-Generating Roads Proposed for California." [Online]. Available: https://inhabitat.com/how-to-grow-an-avocado-tree-fr om-an-avocado-pit/.[Accessed: 04-April-2019].

14. P. Kumar, "Piezo-Smart Roads," Int. J. Enhanc. Res. Sci. Technol. Eng., vol. 2, no. 6, pp. 2319-746365, 2013.

15. A. P. Lepe, "Captación de energía en la carretera mediante transductores piezoeléctricos,” pp. 71-78, 2017.

16. "Power harvesting from railway; apparatus, system and method," 21-Aug-2008.

17. M. González Díaz, "Facultad Ciencias Obtención de energía de las olas empleando materiales piezoeléctricos (Ocean wave power generation using piezoelectric devices)," 2017

18. Z. Lin, "Piezoelectric and triboelectric nanogenerators: Trends and impacts," Nano Today, pp. 8-11, 2018.

19. R. P. Lejano, "Climate change and the relational city," Cities, vol. 85, no. July 2018, pp. 25-29, 2019.

20. W. Jiang, Y. Huang, and A. Sha, "A review of eco-friendly functional road materials," Constr. Build. Mater., vol. 191, pp. 1082-1092, 2018.

21. "The use of piezoelectric for the generation of sustainable energy as a pilot project in a road profile of Bogotá”, 2017 (in Spanish).

22. Ramōnzu besuto serekushon. Shinkō Myūjikku, 2000.

23. T. N. Sequeira and M. S. Santos, "Renewable energy and politics: A systematic review and new evidence," J. Clean. Prod., vol. 192, pp. 553-568, 2018.

24. N. Edomah, Economics of Energy Supply $i s$, no. August. Elsevier Inc., 2018.

25. K. Hansen, "Decision-making based on energy costs: Comparing Levelized Cost of Energy and Energy System costs," Energy Strategy Review, vol. 24, no. April 2019, pp. 68-82, 2019.

26. S. Kumar, A. Gunasekaran, J. Antony, S. Gupta, and S. Bag, "Computers \& Industrial Engineering Systematic literature review of project failures: 
Current trends and scope for future research," Computers \& Industrial Engineering, vol. 127, no. December 2018, pp. 274-285, 2019.

27. "Piezoelectric Harvesting and Sensing 2019-2039: IDTechEx."

28. X. Li and V. Strezov, "Modelling piezoelectric energy harvesting potential in an educational building," Energy Convers. Manag., vol. 85, pp. 435-442, 2014.

29. D. Armando and T. Zapata, "Como Proyecto Piloto En Un Perfil Vial De Bogotá."

30. "Las carreteras 'asfaltadas' con paneles solares fracasan."

31. I. L. White, "La Primera Carretera Solar Se Inaugura En Amsterdam," 2014.

32."Israel: a road that generates electricity!!" [Online].Available:

https://www.natura-medioambiental.com/israel-una-c arretera-que-genera-electricidad/. [Accessed: 04-April-2019] (in Spanish).

33. "Los 8 países con las redes ferroviarias más extensas del mundo | N+1: artículos científicos, noticias de ciencia, cosmos, gadgets, tecnología."

34. "Mitigar el cambio climático con una política energética de la UE limpia | Noticias | Parlamento Europeo." 